\title{
Insulin Signaling, GSK-3, Heat Shock Proteins and the Natural History of Type 2 Diabetes Mellitus: A Hypothesis
}

\author{
PHILIP L. HOOPER
}

\begin{abstract}
Metabolic syndrome and type 2 diabetes are progressive, indolent, multi-organ diseases. Understanding the abnormalities of heat shock proteins (HSPs) in these diseases is paramount to understanding their pathogenesis. In insulin resistant states and diabetes, heat shock factor 1(HSF-1) is low in insulin sensitive tissues, resulting in low Hsp 60, 70, and 90 levels. We propose that low Hsps levels are the result of decreased insulin action leading to less phosphorylation of PI3K, PKB, and glycogen synthase kinase-3 (GSK-3). Importantly, less GSK-3 phosphorylation (and thus more GSK-3 activity) will lower HSF-1. Low Hsps make organs vulnerable to injury, impair the stress response, accelerate systemic inflammation, raise islet amyloid polypeptide, and increase insulin resistance. Feeding this cycle is excess saturated fat and calorie consumption, hypertension, inactivity, aging, and genetic predisposition- all of which are a associated with high GSK-3 activity and low Hsps. Support for the proposed "vicious" cycle is based on the observation that GSK-3 inhibition and Hsp stimulation result in increased insulin sensitivity, reduced accumulation of degenerative proteins with in the cell, improved wound healing, decreased organ damage and improved recovery from vascular ischemia. Recognizing GSK-3 and Hsps in the pathogenesis of insulin resistance, the central common feature of the metabolic syndrome, and type 2 diabetes will expand our understanding of the disease, offering new therapeutic options.
\end{abstract}

\section{What are HSPs?}

$\mathbf{T}^{2}$ The unabated global increase in the prevalence of metabolic syndrome and type 2 diabetes mellitus adds urgency and challenge to researchers and health care providers. New insights are needed in order to treat these progressive, indolent, multi-organ diseases. In this review we propose a previously undescribed progressive cycle that promotes insulin resistance, inflammation, and cell-organ-host vulnerability. Novel elements of the cycle are HSPs, HSF-1, and GSK-3.

Heat shock proteins (HSPs) are proteins that protect the cell from stress. HSP functions include helping refold proteins that have lost their functional conformation, aiding intracellular protein transport, clearing irreversibly damaged proteins or unneeded proteins for liposomal disposal, delaying apoptosis, serving as immune modulators (both stimulating and suppressing inflammation), acting as antioxidants, performing chaperone functions, and maintaining the integrity of cellular components (mitochondria, membrane, and nuclei). HSPs are primarily found intracellularly, but they also function in the extracellular compartment. Evolutionarily, these proteins are re-

Department of Endocrinology, University of Colorado Health Sciences Center, Glen Haven, CO 
markably conserved; the genome sequence coding HSPs in fruit flies is $85 \%$ shared with equivalent molecules in humans. Thought to have originated 2.5 billion years ago, these proteins are found in all prokaryotes and eukaryotes and are essential for survival. The major heat shock proteins are HSP 60, 70, and 90. Within the $70 \mathrm{kDa}$ family of HSPs there are two isoforms-HSP 70 and heat shock cognate 70 (HSC70). HSC 70 is constitutively expressed and mildly induced during stress. HSP 70 (also called HSP 72) is highly induced by stress. Both are cytoprotective and anti-inflammatory. Others mentioned in this review are heme-oxygenase (also known as HSP 32), HSP 27, glucoseregulated proteins (grp 78 and grp 94), and oxygen-regulated protein (orp150).

Importantly, HSF-1 is the major transcriptional factor for HSPs. HSF-1 monitors the structural integrity of intracellular proteins and also negatively regulates cytokine transcription in response to inflammation. In order to be activated and able to bind to HSP gene promoters, HSF-1 must go from its inactive monomeric form to a phosphorylated trimer. HSF-1 is negatively regulated at specific serine phosphorylation sights by glycogen synthase kinase-3 (GSK-3). ${ }^{1}$

\section{HOW ARE HSPS ALTERED IN INSULIN RESISTANCE AND DIABETES?}

Diabetes and insulin resistance are inflammatory states with elevated cytokines, heightened free radical formation, and increased oxidation state, all of which should induce an HSP response. In tissues that are responsive to insulin with increased glucose uptake (skeletal muscle, adipose tissue, liver, and heart), HSP levels and their expression are paradoxically and inappropriately low. Studies in both humans and experimental animals uniformly find reduced HSP expression and/or levels in these insulin sensitive tissues. The first study to report a defect in HSPs in diabetes was by $\mathrm{Ku}$ rucz and coworkers, who observed remarkably low expression of HSP 72 in skeletal muscle of patients with type 2 diabetes, subjects with impaired glucose tolerance, and nondiabetic identical twins whose twin had type 2 diabetes. $\mathrm{Ku}$ rucz noted that the low HSP expression correlated positively with insulin-stimulated glucose uptake and glucose and lipid oxidation. Although the nondiabetic twin siblings had low HSP expression, these subjects also had insulin resistance and perhaps the metabolic syndrome, making it difficult to differentiate a genetic defect versus an acquired defect. Furthermore, as the metabolic abnormality progressed from insulin resistance, to impaired glucose tolerance (IGT), to diabetes, the HSP expression fell further, suggesting an acquired abnormality, rather than simply an inherited one. See Figures 1 and $2 .^{2}$ Bruce and colleagues found that both hemeoxygenase and HSP 72 expression were low in type 2 diabetes patients and that these levels positively correlated with insulin sensitivity. ${ }^{3}$ A genetic expression study of people with and without diabetes found

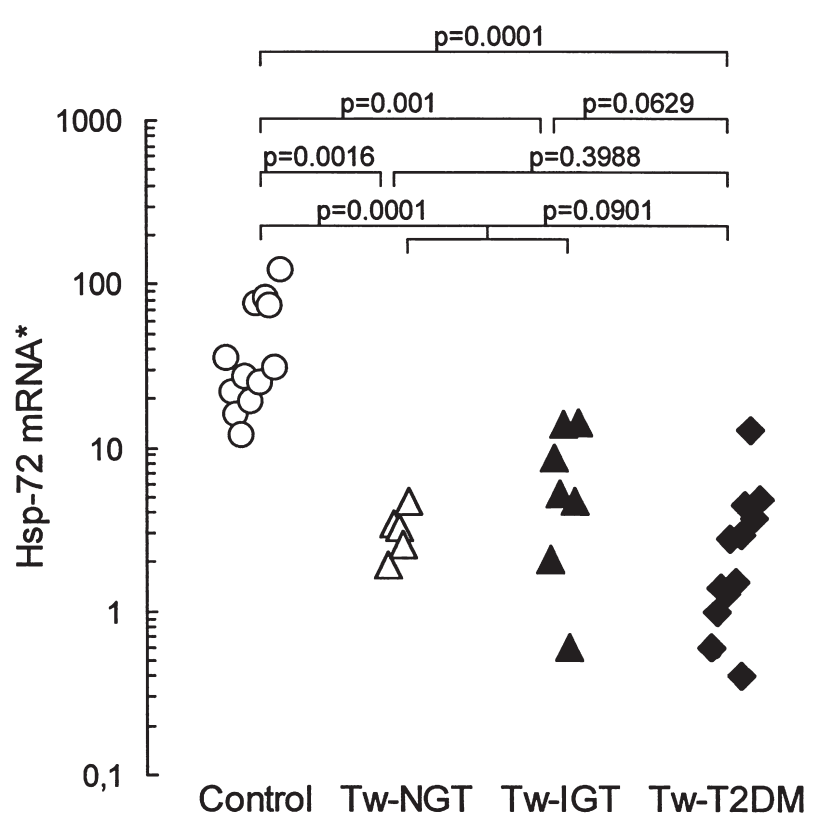

FIG. 1. HSP-72 mRNA levels in muscle biopsies of control subjects and identical monozygotic twins discordant for type 2 diabetes. The amount of HSP-72 messenger RNA was determined using the competitive RT-PCR. Individual data are shown, using $\log _{10}$ scale, as copies of HSP-72 mRNA in $1 \mu \mathrm{g}=$ micrograms total RNA. Statistical differences between the different groups were calculated with the nonparametric Mann-Whitney U test. Comparison of the expression of HSP-72 mRNA between nondiabetic and diabetic individuals in twin-pairs: twins with type 2 diabetes; twins with IGT; twins with NGT. Statistical differences (Wilcoxon-paired test) between nondiabetic and diabetic twins: $P=.0431$ for type 2 diabetes vs. NGT; $P=.1755$ (NS) for type 2 diabetes vs. IGT; $P=.028$ for type 2 diabetes vs. NGT+IGT. ${ }^{*} 106 \mathrm{copy} / \mathrm{n}, \mathrm{g}$ total RNA. Tw, twin; T2DM, type 2 diabetes. (Reproduced with permission from the author). ${ }^{2}$ 


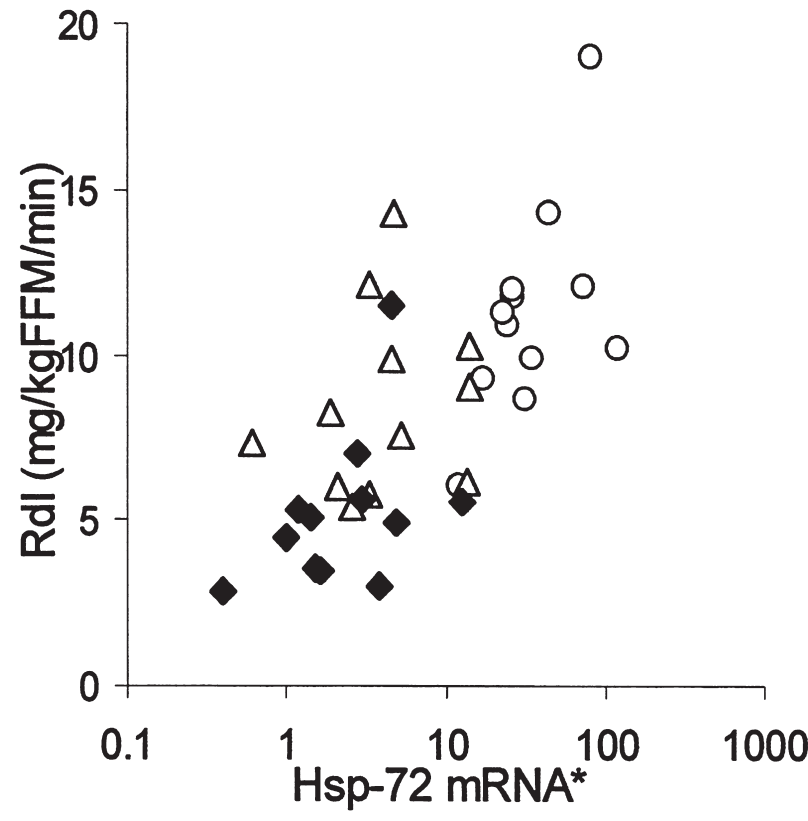

FIG. 2. Correlation between muscle HSP-72 mRNA expression and rates of glucoseturnover, as determined in protocol $2(n=36)$. All of the values are expressed as milligrams per kilogram FFM per minute. control subjects; nondiabetic twins; , twins with type 2 diabetes. Insulin-stimulated total glucose uptake (RdI): control subjects: $\mathrm{R}=0.531$, $P=.078$ NS; nondiabetic subjects: $\mathrm{R}=0.581, P=.0053$; twins: $\mathrm{R}=0.519, P=.0128$; twins with type 2 diabetes: $\mathrm{R}=$ 0.441 , NS. (Reproduced with permission from the author). ${ }^{2}$

lower HSP70 expression in the skeletal muscle of subjects with diabetes. The same study also noted that HSP 70 expression negatively correlated with fasting blood glucose levels. ${ }^{4}$

Studying type 1 diabetic animal models is relevant to understanding type 2 diabetes because it demonstrates the effect of loss of insulin action on HSPs. HSF-1 activation and HSP 72 expression are reduced in liver, heart, and skeletal muscle of diabetic animals in the streptozotocin-induced animal model. The normal exercise-induced rise in HSP expression and HSF-1 activation is blunted in the diabetic animal. ${ }^{5}$ Similarly, hyperthermia-induced activation of HSP 72 is attenuated in the hearts of animals that have streptozotocin-induced diabetes. ${ }^{6}$ In a study of both streptozotocin-induced diabetes and Zucker Fatty rats, HSP 60 levels are lower in the heart and adipose tissue. However, in the kidney, a non-insulin sensitive organ, HSP 60 expression is higher. ${ }^{7}$

In addition to contributing to the progression of type 2 diabetes and insulin resistance, the diabetic consequence of low HSPs increases vulnerability of tissues to injury from harmful stim- uli, including from the inflammatory-oxidative aggression of diabetes itself. ${ }^{8}$ Clinically, low HSP 72 serum levels of trauma patients upon admission to the emergency room predict subsequent mortality during the period of hospitalization. ${ }^{9}$ Relevantly, diabetic trauma patients have markedly higher mortality, ICU length of stays, and ventilatory-assisted days when compared to similar trauma patients without diabetes. ${ }^{10}$ To our knowledge, study of serum levels of HSPs in patients with type 2 diabetes has not been done.

\section{INSULIN ACTION RESULTS IN A RISE IN HSP LEVELS}

Insulin administration increases myocardial HSP 70 expression and protein levels and potentiates HSP synthesis in response to heat shock. The HSP response to a physiological dose of insulin is independent of nitric oxide signaling and is secondary to HSF-1 activation. ${ }^{11}$ Additionally, with a glucose-insulin infusion, HSP 72 expression in skeletal muscle rises four-fold in nondiabetic and diabetic subjects; while, hemeoxygenase rises 70 fold, but only in diabetic patients. ${ }^{3}$ Thus, through insulin action, HSP expression rises. Specifically, we propose that insulin induces the cascade of tyrosine phosphorylation of the insulin receptor, activation of phosphatidylinositol 3-kinase (PI3K), phosphorylation of protein kinase $B$ (PKB), and GSK-3 phosphorylation, which then activates HSF-1 and HSP expression.

\section{BACKGROUND OF GSK-3 AND ITS ROLE IN DISEASES}

As both a highly conserved and ubiquitous protein, GSK-3 has diverse roles that include propagating insulin signaling, determining cell fate through Wnt and hedgehog signaling, regulating cell proliferation and death, and pulsing circadian rhythm. ${ }^{12,13}$ Importantly, GSK-3 also modulates heat shock protein expressionthrough HSF-1. More specifically, phosphorylation of HSF-1 by GSK-3 results in HSF-1 deactivation with a subsequent drop in HSP expression. ${ }^{14}$

With regard to insulin signaling, the insulin cascade leads to PKB phosphorylation of GSK-3 and its deactivation, making it unable to phos- 
phorylate and inactivate glycogen synthase, thereby stimulating glycogen synthesis. ${ }^{15}$ Unlike most kinases, GSK-3 is largely activated in resting, unstimulated cells. Its substrates are therefore highly phosphorylated in the absence of agonists. Thus, the effect of GSK-3's phosphorylation of substrate proteins often leads to inactivation-as is the case with glycogen synthase.

Activation of GSK-3 is found in a number of degenerative diseases including Alzheimer's disease, Parkinson's disease, Huntington's disease, schizophrenia, and diabetes. In the neurological diseases, impaired insulin signaling and GSK-3 activation is associated with abnormal phosphorylation of Tau, amyloid accumulation, abnormal cell function, and premature cell death. ${ }^{12,16}$ In the case of diabetes and the metabolic syndrome, activated GSK-3 itself contributes to insulin resistance. In fact, when muscle GSK-3 is overexpressed in transgenic mice, insulin resistance, glucose intolerance, and elevated free fatty acid and triglyceride levels occur. ${ }^{17}$

\section{HYPOTHESIS}

Our hypothesis is that failure to inactivate GSK-3, as a result of insulin deficiency and impaired insulin signaling (insulin resistance), results in phosphorylation and deactivation of HSF-1. The reduced level of active HSF-1 produces lower HSP levels, increased cytokine activity, progressive interference with insulin

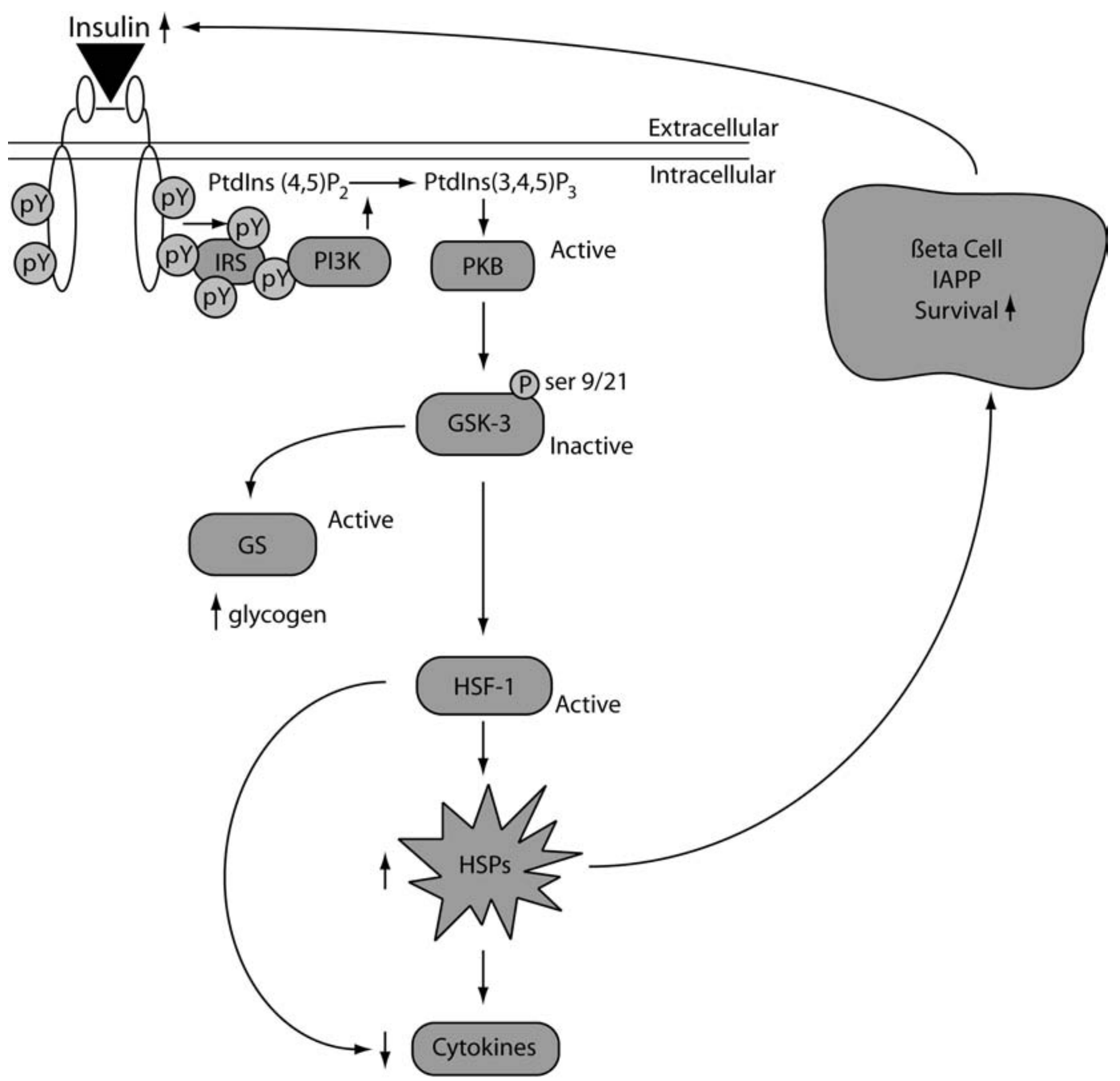

TNF-Alpha, IL-1 ßeta, IL-6, JNK

FIG. 3. The insulin signaling pathway with no insulin resistane. 


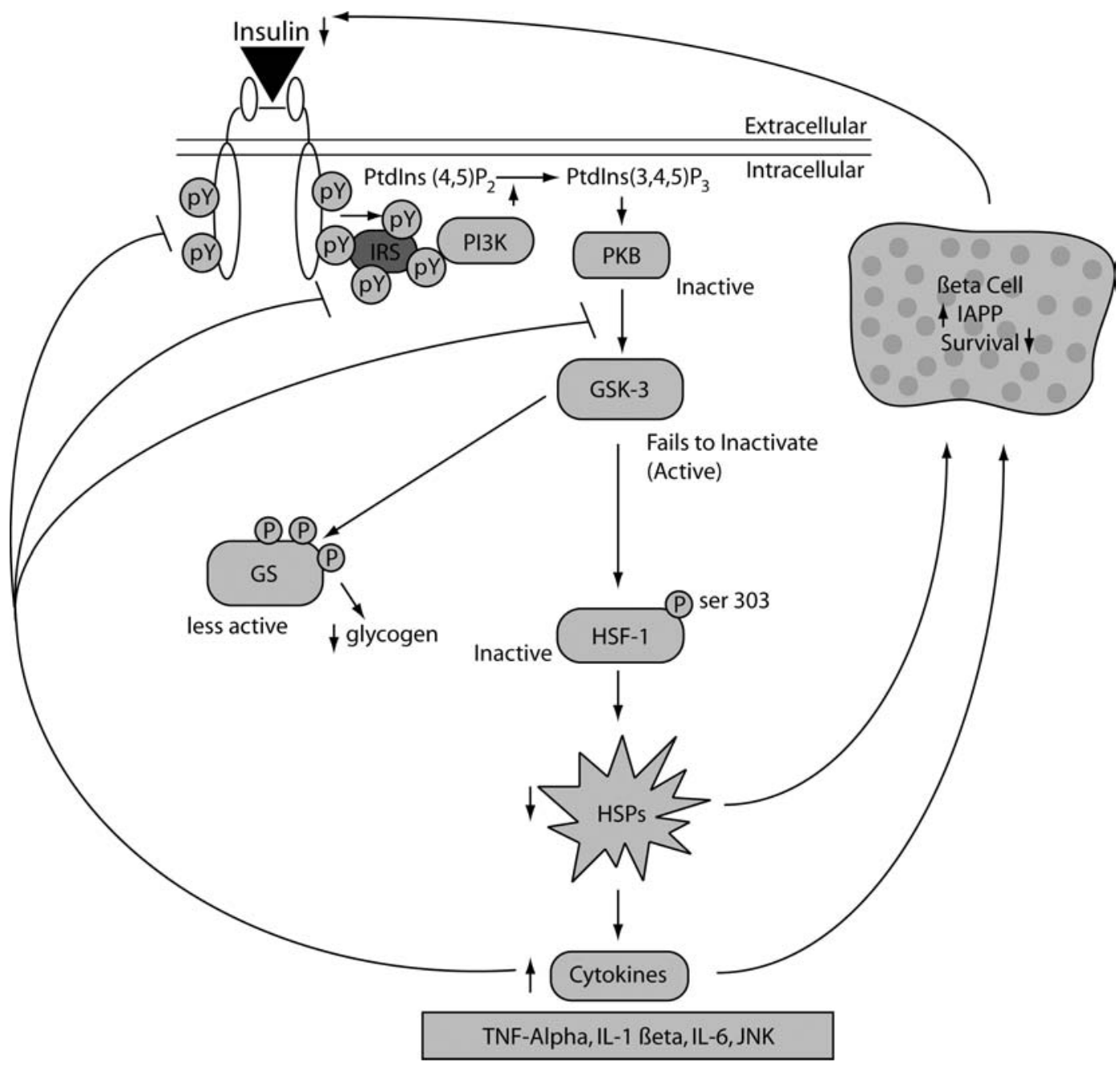

FIG. 4. Type 2 diabetes with decreased insulin, insulin signaling, HSPs, and increased inflammation and beta cell destruction.

signaling, and subsequent organ damageincluding loss of beta-cell function. Thus, a vicious, progressive cycle is initiated that is fed by excessive caloric and saturated fat diet, inactivity, hypertension, aging, and genetic predisposition. Potential spin offs of this cycle are premature aging, atherosclerosis, organ failure, and death. The cycle is decelerated (treated) by factors that either improve insulin signaling, inactivate GSK-3, raise HSP levels, or reduce inflammation. Figure 3 demonstrates how "healthy" insulin signaling activates HSF-1 and thus reduces inflammation and preserves beta cells. On the other hand, Figure 4 shows how disruption of insulin action lowers HSF-1 and thus promotes inflammation which further impairs insulin signaling and beta cell survival. The vicious cycle is shown in Figure 5 with detrimental environmental and genetic factors driving the pin wheel and with disease progression as a spin off. Diet restriction and exercise can slow or block the deleterious spin.

\section{HSPS, INFLAMMATION, AND DIABETES}

The result of lower HSPs in diabetic tissues will increase cytokine action and inflammation. Inflammation plays a major role in the metabolic syndrome and insulin resistance type 2 diabetes: not only are cytokines and acute phase reactants elevated in type 2 diabetes but proinflammatory cytokines (TNF- $\alpha$, IKK- $\beta$, NF- $\kappa$ B) themselves induce insulin resistance. ${ }^{18,19}$ Additionally, the serine/threonine kinase, JNK, plays a role in insulin resistance propagation as well as $\beta$-cell dysfunction and mitochondrial dysfunction. In- 


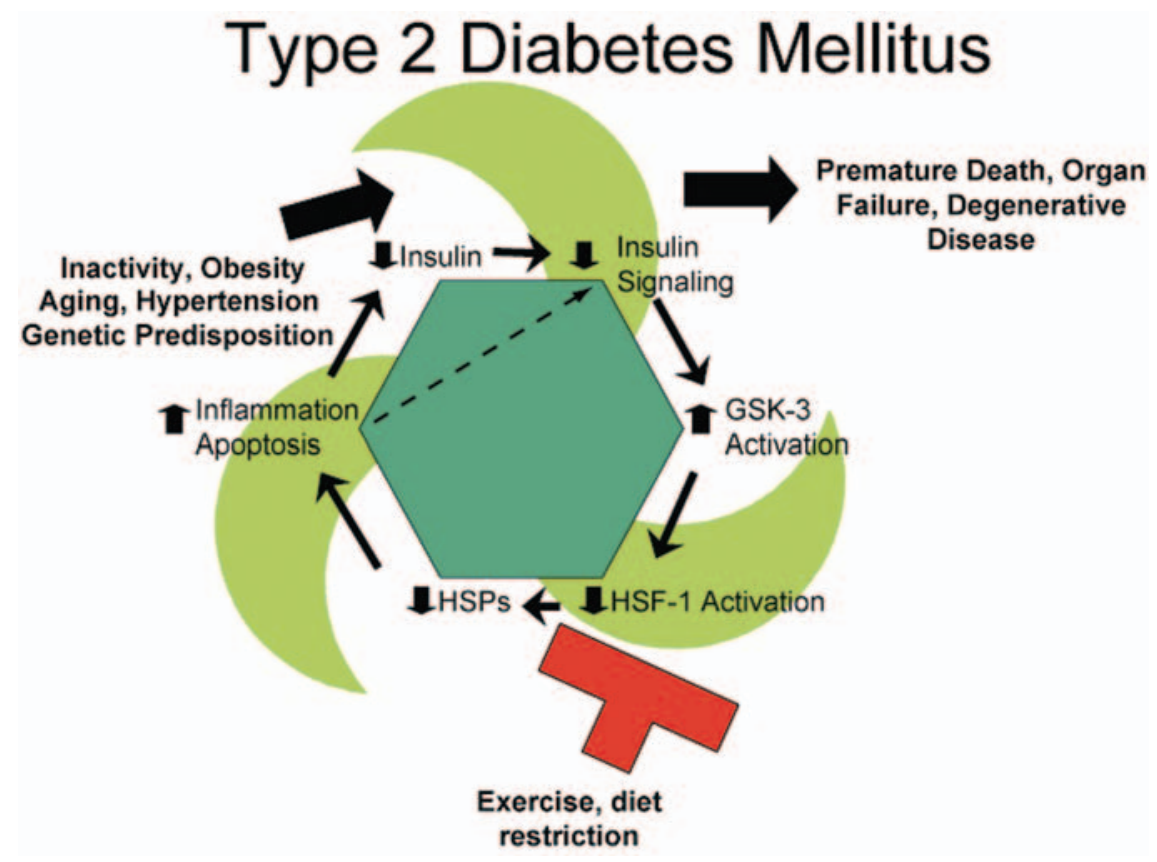

FIG. 5. Type 2 diabetes- the progressive cycle is driven by environmental and genetic factors, results in morbidity and mortality, and reversed by diet and exercise.

deed, IRS-I Ser307 phosphorylation by JNK mediates the inhibitory effect of TNF- $\alpha$ on insulin signaling. ${ }^{20}$

Intracellular HSPs are anti-inflammatory. The loss of anti-inflammatory activity of intracellular HSPs in type 2 diabetes may play a direct role in the induction of insulin resistance and diabetes. In vitro and in vivo studies observe that induction of HSF-1 activity and expression of HSP 70 suppress NF-IL6- and NF- $\kappa \mathrm{B}$-mediated transcription. NF- $\kappa \mathrm{B}$ activation is further suppressed by HSP inhibition of IKK- $\beta$. Additionally, HSP 70 protects against TNF-induced IL-6 production, apoptosis, shock, and death. Finally, HSP 70 blocks JNK activation, and deficiency of HSP 70 activates it. ${ }^{21-23}$ Thus, activation of cytokines as a result of low HSPs impairs insulin signaling and sets in motion the development of insulin resistance and type 2 diabetes.

\section{ENDOPLASMIC RETICULUM STRESS AND $\beta$-CELL SURVIVAL}

With diabetes, ER stress in the $\beta$-cell has been implicated as one mechanism leading to its ultimate failure. Certainly with the high demands for protein synthesis, $\beta$-cell viability is vulnerable to any perturbation in its ER. Oxidative stress and increased insulin production de- mand from diabetes contribute to endoplasmic reticulum stress, protein misfolding, and induction of the unfolded protein response. As the cell's quality control system becomes overwhelmed, conformational changes occur to islet amyloid polypeptide intermediates (IAPP), creating oligomers that are toxic to the $\beta$-cell, promoting apoptosis. ${ }^{24}$ The HSPs of the ER, $\mathrm{BiP} /$ grp78, grp 94, and orp 150, respond to both ER stress and increased protein folding activity. The HSPs' actions prevent protein aggregation. ${ }^{25,26}$ When GSK-3 fails to be inactivated through reduced insulin signaling in ER-stressed $\beta$-cells, apoptosis occurs 27,28 —which we propose is a consequence of impaired HSP response.

\section{GSK-3 INHIBITORS, CARBOHYDRATE METABOLISM, AND $\beta$-CELL SURVIVAL}

Proof of concept for our hypothesized selfsustained cycle is substantiated by the observation that inhibition of GSK-3 improves both insulin resistance and glucose metabolism in type 2 diabetes, provides cytoprotection of both $\beta$-cells and neurons, and raises HSP levels. Presently, more than thirty inhibitors of GSK3 are in drug development. Many are small molecules that can be administered orally and appear to be well tolerated. ${ }^{13}$ 
The beneficial therapeutic effect of GSK-3 inhibitors on insulin resistance is well substantiated by recent studies. Acute exposure to a GSK-3 inhibitor rapidly lowers blood glucose levels and improves glucose disposal after oral or intravenous glucose challenges without causing hypoglycemia or markedly elevating insulin levels in Zucker Diabetic Fatty rats and db/db mice. ${ }^{29}$

With the specific GSK-3 inhibitor, L803-mts, in ob/ob mice chronic administration is associated with increased hepatic and muscle glycogen content, increased muscle GLUT 4 expression, reduced blood glucose levels, improved glucose tolerance, and prevention of age-associated hyperglycemia. The drug has no effect on body weight and no toxicity (Figure 6). ${ }^{30}$ Similarly, another specific GSK-3 inhibitor administered long-term (CT118637) improves glucose intolerance, insulin resistance, and reduces free fatty acid levels in obese Zucker rats. ${ }^{31}$ Finally, a new insulin sensitizer, BGP-15, that exhibits GSK-3 inhibition, ${ }^{32}$ has been studied in insulin resistant nondiabetic human subjects. Four weeks of BGP-15 increases insulin sensitivity assessed by hyperinsulinemic euglycemic clamp. In Goto-Kakizaki rats, long term therapy with the drug (15 weeks) also improves insulin sensitivity and glucose tolerance with no weight gain. In diabetic rats, BGP-15

A

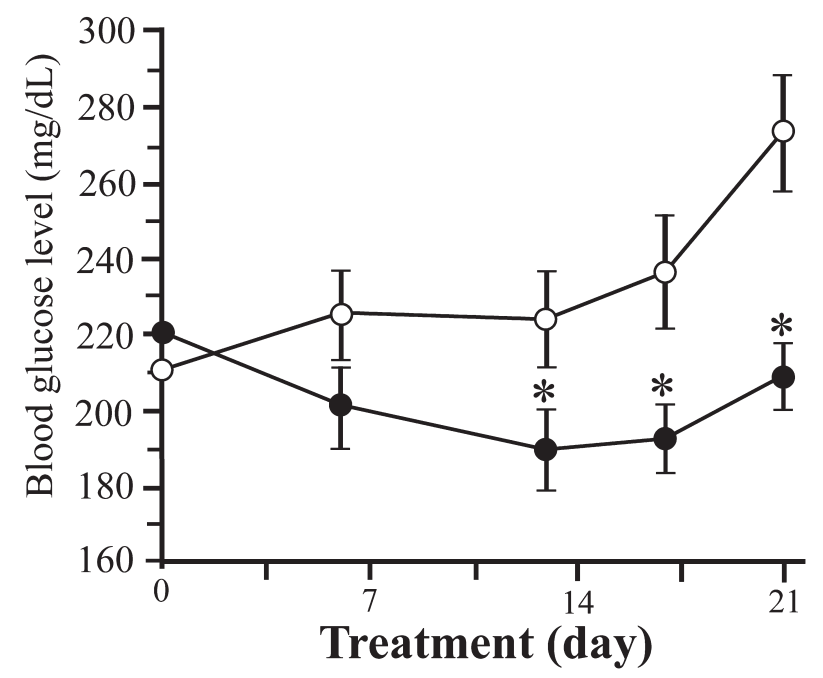

raises tissue HSP levels and improved mitochondrial function in the endothelium. ${ }^{33}$ Previous studies with drugs in the same class as BGP-15 observed that the rise in HSP levels is stimulated by increases in HSF-1 acivity. ${ }^{34}$

Regarding $\beta$-cell survival, knockdown of GSK-3 by RNAi protects $\beta$-cells from ER stress induced death. ${ }^{27}$ Additionally, a recent study of cultured $\beta$-cells observes that GSK-3 inhibitors stimulate $\beta$-cell replication and protects the cells from toxic effects of high concentrations of glucose and saturated fatty acids. ${ }^{35}$

\section{GSK-3 INHIBITORS-NEURO- CYTOPROTECTION AND HSPS}

As mentioned earlier, diabetes is recognized as a conformational disease with $\beta$-cell failure that in many ways mirrors the neuronal death in a number of neuron-degenerative diseases. GSK-3 inhibitors reduce ER stress and reduce toxic amyloid intermediates and apoptosis in the brain, which reduces GSK-3 expression and results in lower ER-stress induced apoptosis. ${ }^{12}$

Few studies have recognized that GSK inhibition in vivo will raise HSF-1 and HSP levels and thus yield a cytoprotective milieu. Two GSK-3 inhibitors, lithium and valproic acid, have been

\section{B}

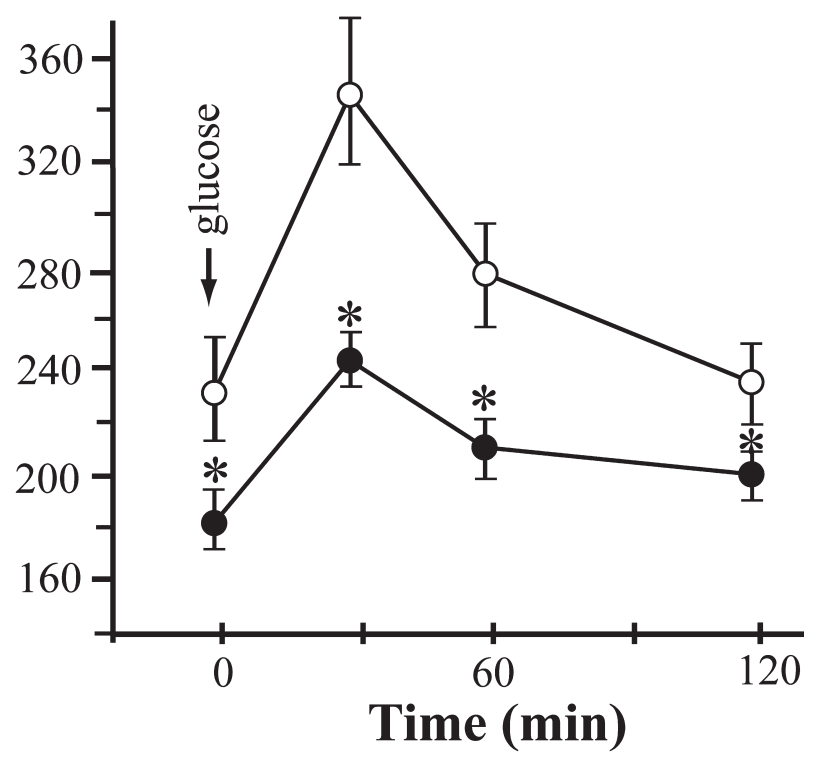

FIG. 6. A, Mean of non-fasting blood glucose levels determined at indicated days. Filled circles, L803-mts treated; open circles, control $\left(n=19-22\right.$ SEM; ${ }^{*}, P<.05$ treated versus controls). B, GTT experiments performed after 3 weeks of treatment with L803-mts. Filled circles, L803-mts treated; open circles, control (n=12-14 S.E.M.; ${ }^{*} P<.05$ treated versus control), Time $=0$; administration of glucose $(1 \mathrm{~g} / \mathrm{kg})$. (Reproduced with permission from the author). ${ }^{30}$ 
studied in a stroke animal model. Both drugs reduce brain tissue damage after a one hour cerebral artery occlusion. The reduction in tissue damage directly correlates with rises in HSP 70 expression and protein levels in brain tissue in response to therapy. ${ }^{36,37}$ More recently, in a cell culture study, two different GSK-3 inhibitors raise HSF-1 levels and protect against oxidative stress induced neuronal death. ${ }^{37}$

\section{HEAT SHOCK AND DM}

Kurucz's interest in studying HSPs, insulin resistance, and type 2 diabetes was, in part, stimulated by our work on heat shock in patients with diabetes (personal communication, KurulzI IVAX Drug Research Institute, Budapest, Hungary). In our study on patients with type 2 diabetes, immersion in a hot tub six days a week for three weeks dropped their fasting glucose levels and hemoglobin A1c levels. The hot water raised the subjects' oral temperature. Diet, exercise, and medication were controlled during the study. ${ }^{39}$ HSP expression was not measured but similar heat exposure in animals raises HSP expression. ${ }^{40}$ Recently, a rat study found that weekly exposure to $15 \mathrm{~min}$ utes of heat shock with elevated core temperature to $41^{\circ} \mathrm{C}$ was able to block high fat diet induction of insulin resistance, glucose intolerance, and JNK activation. ${ }^{23}$ Interestingly and relevantly, heat shock itself activates the PI3K/AKT pathway yielding GSK-3 inhibition and a rise in HSP expression. ${ }^{41}$

While our study of diabetes was prompted by the hypothesis that hot tub immersion would simulate exercise and improve insulin resistance, for more than a century spa therapy for type 2 diabetes was embraced in Russia and Eastern Europe. Numerous studies published in the nonEnglish literature documented major glycemic improvements with spa therapy. ${ }^{42,43}$ Unfortunately, most of the studies included changes in diet and exercise while bathing in hot waters. On the other hand, a recent study of people with cardiovascular risk factors found that daily saunawarm blanket therapy that raised body temperature by $1^{\circ} \mathrm{C}$ reduces fasting glucose levels significantly over a two week period. Diet and exercise were unaltered during that trial. ${ }^{44}$

\section{AGENTS OR CONDITIONS THAT ALTER HSPS AND DIABETES}

Drugs, lifestyles, and genetic factors that raise HSP levels are associated with reduced insulin resistance; conversely, the opposite is the case with those that lower HSP levels. The ingestion of saturated fat is associated with low HSP levels and unsaturated fat with higher HSP levels. ${ }^{45}$ He proposes that $\operatorname{Vigh}^{46,47}$ has hypothesized that membrane fluidization stimulates HSP synthesis via a signal similar to a heat shock hyperfluidization of mammalian cell membranes acts as a signal to initiate the heat shock protein response. On the other hand, stiffer membranes resulting from saturated fat ingestion result in reduced HSP levels. ${ }^{45,46}$ Furthermore, high free fatty acids (FFAs) and their toxic metabolites (like ceramide) can produce loss of insulin signaling, activate GSK-3, and, we propose, lower HSF-1 and HSPs. ${ }^{47}$ In addition, exercise that raises body temperature increases HSP levels, whereas sedentary behavior reduces them. ${ }^{48}$ Low caloric diets stimulate HSP production and are associated with improved mitochondrial function, insulin sensitivity, and longer life span. ${ }^{49}$ Presumably, high calorie diets and obesity would correspondingly have the opposite effect of low calorie diets. With aging, the HSP response to stress is blunted while the propensity to develop diabetes increases. ${ }^{50}$

Hypertension is associated with insulin resistance and impaired insulin signaling. ${ }^{51}$ Angiotensin II increases inflammatory cytokines, particularly NF- $\kappa \mathrm{B}$, which can impair insulin signaling. Relevantly, heat shock, through activating HSPs, reduces hypertension-induced inflammation. ${ }^{52}$ In patients with hypertension, Pockley and coworkers found that carotid intima-media thickness progression was inversely related to their serum HSP 70 levels. ${ }^{53}$

Some genetic predisposition to type 2 diabetes may arise from alteration in HSP gene expression. Diseases with HSP gene alterations ${ }^{54}$ that are associated with type 2 diabetes include Williams Syndrome, ${ }^{55}$ Charcot-Marie-Tooth disease, ${ }^{56}$ Alström Syndrome, and Bardet-Biedl Syndrome. ${ }^{57}$ The Pima Indians, who are unusually prone to the development of diabetes, have polymorphisms of orp 150 that are associated with insulin resistance. ${ }^{58}$ Sense orp 150 
overexpression in the liver of obese diabetic mice significantly improved insulin resistance and ameliorated glucose tolerance. Conversely, expression of antisense orp 150 in the liver of normal mice decreased insulin sensitivity. ${ }^{59}$

Mestril and Dillmann have developed an HSP 70 transgenic mouse line that is resistant to ischemic as well as to traumatic insults. ${ }^{60,61}$ When these overexpressing HSP 70 mice are fed a high fat diet, they remain insulin sensitive with no diet-induced progression to glucose intolerance and no JNK activation. ${ }^{23}$

A number of agents block GSK-3, raise HSPs, improve insulin resistance and, in some cases, improve diabetic complications. The definitive mechanisms by which many of these agents improve glucose metabolism have not been identified. A possible mechanism for their action may be due to a rise in the anti-inflammatory, cytoprotective HSPs. The list includes thiazolidinediones, losartan, statins, carvedilol, bimoclomol, and resveratrol. ${ }^{62}$ Full discussion of these agents is beyond the scope of this paper. On a final note, the ability of insulin to induce higher HSP levels may at least partially explain the remarkable improvements observed in morbidity and mortality when insulin is infused in critically ill patients with or without known diabetes. ${ }^{62}$

\section{ACKNOWLEDGMENT}

Individuals that I would like to acknowledge for their contribution to the preparation of the manuscript: Peter Watson, Mark Nicolls, Daniel Porte, Lazlo Vigh, Mark Febbraio, Laszlo Vigh, Boris Draznin, Kylie Kavanagh, Bob Honeycutt.

\section{CONCLUSION}

We have presented here a description of a selfperpetuating cycle that accelerates with high fat, high calorie diets, hypertension, sedentary behavior, genetic predisposition, and aging. Results of the cycle include insulin resistance, diabetic complications, organ failure, premature aging, neurodegenerative diseases, and vulnerability to premature death. Impaired insulin signaling, activation of GSK-3, and reduced HSP levels are central defects associated with meta- bolic syndrome and type 2 diabetes. Interventions such as exercise, low fat and calorie diets, and HSP raising agents (like GSK-3 inhibitors) decelerate the cycle and result in improved clinical outcomes, in part because they positively modify core pathophysiologic defects of type 2 diabetes and the metabolic syndrome.

\section{REFERENCES}

1. Tytell M, Hooper PL. Heat shock proteins: new keys to the development of cytoprotective therapies. Expert Opin Ther Targets 2001;5:267-287.

2. Kurucz I, Morva A, Vaag A, Eriksson KF, Huang X, Groop L, Koranyi L. Decreased expression of heat shock protein 72 in skeletal muscle of patients with type 2 diabetes correlates with insulin resistance. $D i$ abetes 2002;51:1102-1109.

3. Bruce CR, Carey AL, Hawley JA, Febbraio MA. Intramuscular heat shock protein 72 and heme oxygenase- 1 mRNA are reduced in patients with type 2 diabetes: evidence that insulin resistance is associated with a disturbed antioxidant defense mechanism. Diabetes 2003;52:2338-2345.

4. Patti ME, Butte AJ, Crunkhorn S, Cusi K, Berria R, Kashyap S, Miyazaki Y, Kohane I, Costello M, Saccone R, Landaker EJ, Goldfine AB, Mun E, DeFronzo R, Finlayson J, Kahn CR, Mandarino LJ. Coordinated reduction of genes of oxidative metabolism in humans with insulin resistance and diabetes: Potential role of PGC1 and NRF1. Proc Natl Acad Sci U S A 2003;100:8466-8471.

5. Atalay M, Oksala NK, Laaksonen DE, Khanna S, Nakao C, Lappalainen J, Roy S, Hanninen O, Sen CK. Exercise training modulates heat shock protein response in diabetic rats. J Appl Physiol 2004;97:605-611.

6. Shinohara T, Takahashi N, Ooie T, Hara M, Shigematsu S, Nakagawa M, Yonemochi H, Saikawa T, Yoshimatsu H. Phosphatidylinositol 3-kinase-dependent activation of akt, an essential signal for hyperthermia-induced heat-shock protein 72 , is attenuated in streptozotocin-induced diabetic heart. Diabetes 2006;55:1307-1315.

7. Shan YX, Yang TL, Mestril R, Wang PH. Hsp10 and Hsp60 suppress ubiquitination of insulin-like growth factor-1 receptor and augment insulin-like growth factor-1 receptor signaling in cardiac muscle: implications on decreased myocardial protection in diabetic cardiomyopathy. J Biol Chem 2003;278:45492-45498.

8. Hooper PL, Hooper JJ. Loss of defense against stress: diabetes and heat shock proteins. Diabetes Technol Ther 2005;7:204-208.

9. Pittet JF, Lee H, Morabito D, Howard MB, Welch WJ, Mackersie RC. Serum levels of Hsp 72 measured early after trauma correlate with survival. J Trauma 2002; 52:611-617; discussion 617.

10. Bochicchio GV, Sung J, Joshi M, Bochicchio K, Johnson SB, Meyer W, Scalea TM. Persistent hyper- 
glycemia is predictive of outcome in critically ill trauma patients. J Trauma 2005;58:921-924.

11. Li G, Ali IS, Currie RW. Insulin induces myocardial protection and Hsp70 localization to plasma membranes in rat heart. Am J Physiol Heart Circ Physiol 2006;291:H1709-H1721.

12. Frame S, Zheleva D. Targeting glycogen synthase kinase-3 in insulin signalling. Expert Opin Ther Targets 2006;10:429-444.

13. Meijer L, Flajolet M, Greengard P. Pharmacological inhibitors of glycogen synthase kinase 3. Trends Pharmacol Sci 2004;25:471-480.

14. Calderwood SK. Regulatory interfaces between the stress protein response and other gene expression programs in the cell. Methods 2005;35:139-148.

15. Embi N, Rylatt DB, Cohen P. Glycogen synthase kinase-3 from rabbit skeletal muscle. Separation from cyclic-AMP-dependent protein kinase and phosphorylase kinase. Eur J Biochem 1980;107:519-527.

16. Zhao Z, Ksiezak-Reding H, Riggio S, Haroutunian V, Pasinetti GM. Insulin receptor deficits in schizophrenia and in cellular and animal models of insulin receptor dysfunction. Schizophr Res 2006;84:1-14.

17. Pearce NJ, Arch JR, Clapham JC, Coghlan MP, Corcoran SL, Lister CA, Llano A, Moore GB, Murphy GJ, Smith SA, Taylor CM, Yates JW, Morrison AD, Harper AJ, Roxbee-Cox L, Abuin A, Wargent E, Holder JC. Development of glucose intolerance in male transgenic mice overexpressing human glycogen synthase kinase-3beta on a muscle-specific promoter. Metabolism 2004;53:1322-1330.

18. Haffner SM. The metabolic syndrome: inflammation, diabetes mellitus, and cardiovascular disease. Am J Cardiol 2006;97:3A-11A.

19. Cai D, Yuan M, Frantz DF, Melendez PA, Hansen L, Lee J, Shoelson SE. Local and systemic insulin resistance resulting from hepatic activation of IKK-beta and NF-kappaB. Nat Med 2005;11:183-190.

20. Aguirre V, Uchida T, Yenush L, Davis R, White MF. The c-Jun NH(2)-terminal kinase promotes insulin resistance during association with insulin receptor substrate-1 and phosphorylation of Ser(307). J Biol Chem 2000;275:9047-9054.

21. Yenari MA, Liu J, Zheng Z, Vexler ZS, Lee JE, Giffard RG. Antiapoptotic and anti-inflammatory mechanisms of heat-shock protein protection. Ann N Y Acad Sci 2005;1053:74-83.

22. Kim YK, Suarez J, Hu Y, McDonough PM, Boer C, Dix DJ, Dillmann WH. Deletion of the inducible $70-\mathrm{kDa}$ heat shock protein genes in mice impairs cardiac contractile function and calcium handling associated with hypertrophy. Circulation 2006;113: 2589-2597.

23. Chung JCS, Watt MJ, Mestril R, Febbraaio MA. HSP72 protects against diet-induced insulin reistance by blocking JNK phosporylation (Abstract). Diabetes2006;55:1469A.

24. Hayden MR, Tyagi SC, Kerklo MM, Nicolls MR Type 2 diabetes mellitus as a conformational disease. JOP 2005;6:287-302.
25. Oyadomari S, Araki E, Mori M. Endoplasmic reticulum stress-mediated apoptosis in pancreatic betacells. Apoptosis 2002;7:335-345.

26. Oyadomari S, Mori M. Roles of CHOP/GADD153 in endoplasmic reticulum stress. Cell Death Differ 2004; 11:381-389.

27. Srinivasan S, Ohsugi M, Liu Z, Fatrai S, Bernal-Mizrachi E, Permutt MA. Endoplasmic reticulum stress-induced apoptosis is partly mediated by reduced insulin signaling through phosphatidylinositol 3-kinase/Akt and increased glycogen synthase kinase-3beta in mouse insulinoma cells. Diabetes 2005;54:968-975.

28. Muller D, Huang GC, Amiel S, Jones PM, Persaud SJ. Identification of insulin signaling elements in human \{beta\}-Cells: Autocrine regulation of insulin gene expression. Diabetes 2006;55:2835-2842.

29. Cline GW, Johnson K, Regittnig W, Perret P, Tozzo E, Xiao L, Damico C, Shulman GI. Effects of a novel glycogen synthase kinase-3 inhibitor on insulin-stimulated glucose metabolism in Zucker diabetic fatty (fa/fa) rats. Diabetes 2002;51:2903-2910.

30. Kaidanovich-Beilin O, Eldar-Finkelman H. Long-term treatment with novel glycogen synthase kinase-3 inhibitor improves glucose homeostasis in ob/ob mice: molecular characterization in liver and muscle. J Pharmacol Exp Ther 2006;316:17-24.

31. Dokken BB, Henriksen EJ. Chronic selective glycogen synthase kinase-3 inhibition enhances glucose disposal and muscle insulin action in prediabetic obese Zucker rats. Am J Physiol Endocrinol Metab 2006;291: E207-E213.

32. Vigh L, Torok Z, Balogh G, Glatz A, Piotto S, Horvath I. Adv Exp Med Biol 2007;594:114-131.

33. Kolonics ALNP, Peitl B, Bajza A, Jaszlits L, Laszlo L, Haorvath T, Kulcscar E, Porszasz R, Paragh G, Bernath S, Literati B, Koranyi L, Szilvassy Z, Tory K, Roth J. BGP-15, a new type of insulin sensitizer (Abstract). Diabetes 2006;55:2091A.

34. Hargitai J, Lewis H, Boros I, Racz T, Fiser A, Kurucz I, Benjamin I, Vigh L, Penzes Z, Csermely P, Latchman DS. Bimoclomol, a heat shock protein co-inducer, acts by the prolonged activation of heat shock factor1. Biochem Biophys Res Commun 2003;307:689-695.

35. Mussmann R, Geese M, Harder F, Kegel S, Andag U, Lomow A, Burk U, Onichtchouk D, Dohrmann C, Austen M. Inhibition of GSK 3 promotes replication and survival of pancreatic beta cells. J Biol Chem 2007;282:12030-12037.

36. Ren M, Leng Y, Jeong M, Leeds PR, Chuang DM. Valproic acid reduces brain damage induced by transient focal cerebral ischemia in rats: potential roles of histone deacetylase inhibition and heat shock protein induction. J Neurochem 2004;89:1358-1367.

37. Ren M, Senatorov VV, Chen RW, Chuang DM. Postinsult treatment with lithium reduces brain damage and facilitates neurological recovery in a rat ischemia/ reperfusion model. Proc Natl Acad Sci U S A 2003; 100:6210-6215.

38. Lee KY, Koh SH., Noh MY., Park KW, Lee YJ, Kim $\mathrm{SH}$. Glycogen synthase kinase-3beta activity plays 
very important roles in determining the fate of oxidative stress-inflicted neuronal cells. Brain Res 2007; 1129:89-99.

39. Hooper PL. Hot-tub therapy for type 2 diabetes mellitus. N Engl J Med 1999;341:924-925.

40. Okada M, Hasebe N, Aizawa Y, Izawa K, Kawabe J, Kikuchi K. Thermal treatment attenuates neointimal thickening with enhanced expression of heat-shock protein 72 and suppression of oxidative stress. Circulation 2004;109:1763-1768.

41. Maroni P, Bendinelli P, Tiberio L, Rovetta F, Piccoletti $\mathrm{R}$, Schiaffonati L. In vivo heat-shock response in the brain: signalling pathway and transcription factor activation. Brain Res Mol Brain Res 2003;119:90-99.

42. Davydova OB, Turova EA, Teniaeva EA. [The balneotherapy of diabetes mellitus (Russian)]. Vopr Kurortol Fizioter Lech Fiz Kult 1994;2:44-51.

43. Jandik J. [Spa treatment of diabetes mellitus (Russian)]. Sb Ved Pr Lek Fak Karlovy Univerzity Hradci Kralove 1980;23:497-510.

44. Biro S, Masuda A, Kihara T, Tei C. Clinical implications of thermal therapy in lifestyle-related diseases. Exp Biol Med (Maywood), 2003;228:1245-1249.

45. Csont T, Balogh G, Csonka C, Boros I, Horvath I, Vigh L, Ferdinandy P. Hyperlipidemia induced by high cholesterol diet inhibits heat shock response in rat hearts. Biochem Biophys Res Commun 2002;290:1535-1538.

46. Balogh G, Horvath I, Nagy E, Hoyk Z, Benko S, Bensaude $\mathrm{O}$, Vigh L. The hyperfluidization of mammalian cell membranes acts as a signal to initiate the heat shock protein response. FEBS J 2005;272:60776086.

47. Vigh L, Maresca B, Harwood JL. Does the membrane's physical state control the expression of heat shock and other genes? Trends Biochem Sci 1998;23:369-374.

48. Chavez JA, Knotts TA, Wang LP, Li G, Dobrowsky RT, Florant GL, Summers SA. A role for ceramide, but not diacylglycerol, in the antagonism of insulin signal transduction by saturated fatty acids. J Biol Chem 2003;278:10297-10303.

49. Ascensao A, Ferreira R, Magalhaes J. Exercise-induced cardioprotection-biochemical, morphological and functional evidence in whole tissue and isolated mitochondria. Int J Cardiol 2007;117:16-30.

50. Colotti C, Cavallini G, Vitale RL, Donati A, Maltinti M, Del Ry S, Bergamini E, Giannessi D. Effects of aging and anti-aging caloric restrictions on carbonyl and heat shock protein levels and expression. Biogerontology 2005;6:397-406.

51. Singh R, Kolvraa S, Bross P, Christensen K, Gregersen $\mathrm{N}$, Tan Q, Jensen UB, Eiberg H, Rattan SI. Heatshock protein 70 genes and human longevity: a view from Denmark. Ann N Y Acad Sci 2006;1067: 301-308.

52. Sowers JR. Insulin resistance and hypertension. Am J Physiol Heart Circ Physiol 2004;286: H1597-H1602.

53. Chen Y, Arrigo AP, Currie RW. Heat shock treatment suppresses angiotensin II-induced activation of NFkappaB pathway and heart inflammation: a role for
IKK depletion by heat shock? Am J Physiol Heart Circ Physiol 2004;287:H1104-H1114.

54. Pockley AG, Georgiades A, Thulin T, de Faire U, Frostegard J. Serum heat shock protein 70 levels predict the development of atherosclerosis in subjects with established hypertension. Hypertension 2003;42: 235-238.

55. Macario AJ, Conway de Macario E. Sick chaperones, cellular stress, and disease. N Engl J Med 2005;353: 1489-1501.

56. Merla G, Howald C, Antonarakis SE, Reymond A. The subcellular localization of the ChoRE-binding protein, encoded by the Williams-Beuren syndrome critical region gene 14 , is regulated by $14-3-3$. Hum Mol Genet 2004;13:1505-1514.

57. Koc F, Sarica Y, Yerdelen D, Baris I, Battaloglu E, Sert M. A large family with Charcot-Marie-Tooth Type 1a and Type 2 diabetes mellitus. Int J Neurosci 2006;116: 103-114.

58. Hearn T, Spalluto C, Phillips VJ, Renforth GL, Copin N, Hanley NA, Wilson DI. Subcellular localization of ALMS1 supports involvement of centrosome and basal body dysfunction in the pathogenesis of obesity, insulin resistance, and type 2 diabetes. Diabetes 2005;54:1581-1587.

59. Kovacs P, Yang X, Permana PA, Bogardus C, Baier LJ. Polymorphisms in the oxygen-regulated protein 150 gene (ORP150) are associated with insulin resistance in Pima Indians. Diabetes 2002;51:1618-1621.

60. Nakatani Y, Kaneto H, Kawamori D, Yoshiuchi K, Hatazaki M, Matsuoka TA, Ozawa K, Ogawa S, Hori M, Yamasaki Y, Matsuhisa M. Involvement of endoplasmic reticulum stress in insulin resistance and diabetes. J Biol Chem 2005;280:847-851.

61. Mestril R, Giordano FJ, Conde AG, Dillmann WH. Adenovirus-mediated gene transfer of a heat shock protein 70 (hsp 70i) protects against simulated ischemia. J Mol Cell Cardiol 1996;28:2351-2358.

62. Miyabara EH, Martin JL, Griffin TM, Moriscot AS., Mestril R. Overexpression of inducible 70-kDa heat shock protein in mouse attenuates skeletal muscle damage induced by cryolesioning. Am J Physiol Cell Physiol 2006;290:C1128-C1138.

63. van den Berghe G, Wouters P, Weekers F, Verwaest C, Bruyninckx F, Schetz M, Vlasselaers D, Ferdinande $\mathrm{P}$, Lauwers $\mathrm{P}$, Bouillon R. Intensive insulin therapy in the critically ill patients. N Engl J Med 2001;345: 1359-1367.

Address reprint requests to: Dr. Philip L. Hooper Department of Endocrinology University of CO Health Sciences Center PO Box 245

Glen Haven, CO 80532

E-mail: phoopermd@gmail.com 